\title{
Managing a change in rock mass response to mining at the Frog's Leg underground mine
}

\author{
J Mgumbwa Evolution Mining, Australia \\ A Page Evolution Mining, Australia \\ L Human SRK Consulting (Australasia) Pty Ltd, Australia \\ MJ Dunn Evolution Mining, Australia
}

\begin{abstract}
Evolution Mining's Frog's Leg underground mine experienced an increase in the number of seismic events and rockburst occurrences during 2015. This was due to increased stress levels due to increasing mining depth and unfavourable mining geometry (mining the sole remaining diminishing pillar) as well as interaction with some seismically active crosscutting geological structures. At the time, the extraction sequence was transitioning from central access to an end-on retreat sequence with stopes in the diminishing pillar being extracted as triple lifts. Initially, a triple lift extraction methodology was implemented to eliminate the exposure of personnel and equipment to potentially seismically active ground as the closure pillar was extracted. All production activities for the closure pillar were conducted outside the oredrives from a drive situated in the hanging wall.

Intense episodes of seismic activity occurred during the third and fourth quarters of 2015 as well as early in the first quarter of 2016 while the closure pillar was being extracted. During this period, two rockbursts occurred; after the second rockburst, management decided to temporarily halt production activities in the area pending geotechnical investigation and the development of a new extraction strategy.

A Geotechnical Review Board (GRB) was formed to review and evaluate the situation to date and provide guidance on: the extraction sequence, ground support design and implementation, and seismic monitoring requirements. Following the GRB evaluation, a program of works was initiated including assessment of various extraction sequences and dynamic ground support design. Subsequently, these have been implemented and mining activities have resumed.

This paper provides an overview of the mining practices that led to increased seismicity and rockbursts as well as measures that were implemented to mitigate the hazard associated with increased mining-induced seismicity and increasing stress levels.
\end{abstract}

Keywords: seismicity, high stress, closure pillar, extraction sequence, ground support

\section{Introduction}

Evolution Mining's Frog's Leg underground mine experienced an increase in the number of seismic events and rockburst occurrences during 2015 and early 2016. This paper provides an overview of how mine technical services personnel and management have responded to the challenges associated with the increase in mining-induced seismicity.

\subsection{Mine description}

The Frog's Leg mine is located within the Kundana mining district, approximately $20 \mathrm{~km}$ west of Kalgoorlie, Western Australia. The mine forms part of the Evolution Mining's Mungari operations, who also owns and operate the White Foil open pit and the Mungari processing plant. The mine started as an open pit that was 
mined in 2004 and terminated in 2005. An underground operation commenced in 2007 and has since been continuously in operation.

The ground surface is at $8,340 \mathrm{mRL}$ with depth below surface increasing as the level number decreases. Underground workings are accessed through a single decline with the portal located at the bottom of the Frog's Leg open pit. The decline branches at the 8270 Level with separate access to the northern and southern mineralised zones. The two declines are joined by a link drive on the 8093 Level. The current decline development is approximately $600 \mathrm{~m}$ below the surface with the lowest stoping level at about $550 \mathrm{~m}$. The mine grid north is $35^{\circ}$ west of true north and the orebody strikes approximately mine grid north-south.

\subsection{Regional and local geology}

The Kundana mining district is a world class gold camp in the Archaean Norseman Wiluna Belt of the Yilgarn craton. This granite-greenstone belt is approximately $600 \mathrm{~km}$ in length and is characterised by a thick, rift-controlled accumulation of ultramafic, mafic and felsic volcanic, intrusive and sedimentary rocks. Metamorphism ranges from greenschist to amphibolite grade. Successions of greenstone occur in north trending, elongate structural terranes that are bounded by north-northwest trending faults.

The Frog's Leg orebody is located within a series of northwest trending complex structures associated with the Zuleika shear zone. There are multiple strike slip structures that offset the ore dextrally. One example is the Mary Fault, which truncates the ore at the northern end of the deposit and is one of the most seismically active structures at Frog's Leg. Ore zones are generally associated with the sheared lithological contact between volcaniclastics and catrock over a strike length of $1,200 \mathrm{~m}$. Zones reach a maximum thickness where a dilational jog occurs on a bend in the contact structure. Stacked internal ore zones of varying lithology and mineralisation style located between the hanging wall lode and the contact lode in the dilational jog (Figure 1). Lodes are steeply west-dipping ( $75^{\circ}$ to sub-vertical) and vary in width between 2 and $20 \mathrm{~m}$. Gold mineralisation is associated with intense shear deformation, quartz veining and brecciation.

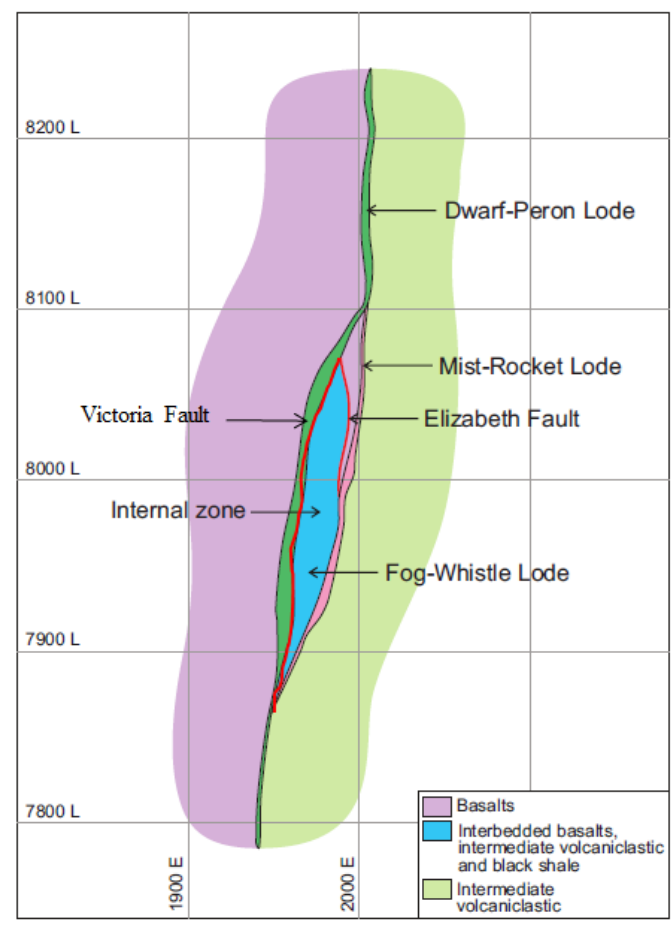

Frog's Leg cross section $12635 \mathrm{mN}$ (looking north)

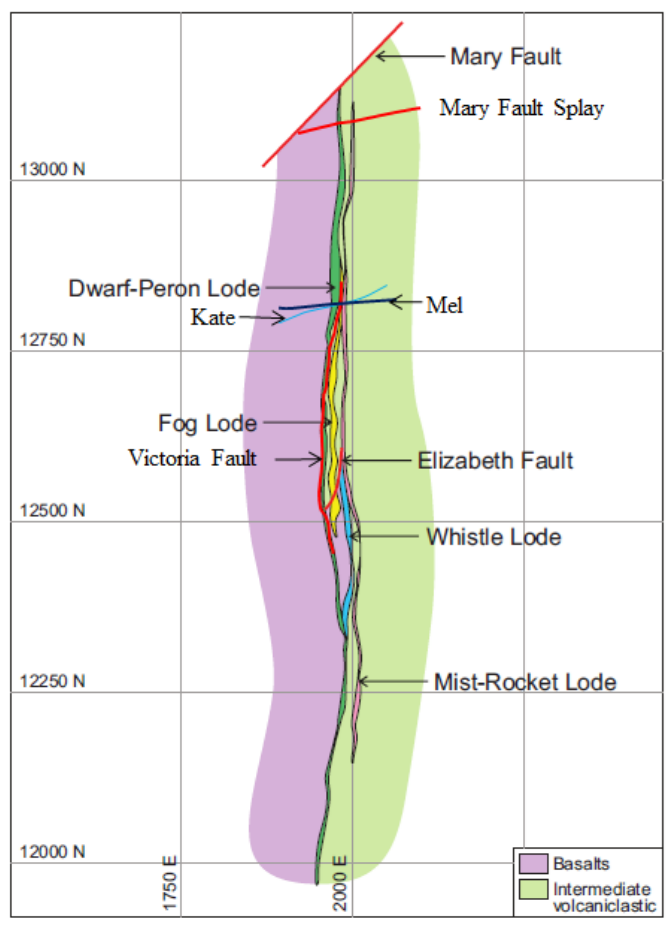

Plan view in the flexture @ the 7975 m RL

Figure 1 Geological cross-section and plan view through Frog's Leg deposit showing major geological structures and ore lodes 
Frog's Leg has two main mineralised zones; the Mist lode to the north and the Rocket lode to the south. Near surface, the Mist and Rocket orebodies are separated by a low grade zone, although the structure does appear to continue through this area. Below the 8050 Level, the two orebodies link together with economic material extending from the Mist to the Rocket. This zone, where the two orebodies link together, is called the dilation zone and is very wide $(>30 \mathrm{~m})$ and extends from the 8050 Level to the 7950 Level. Below the 7950 Level, the two ore zones separate once again, with a wide shale unit present in the hanging wall having a negative impact on grade.

\subsection{Geological discontinuities}

Geological and geotechnical mapping has been conducted in an attempt to identify the major and minor geological discontinuities that control the failure mechanisms. Microseismic data in conjunction with routine underground mapping is used for validating hazardous structures and identifying previously unidentified structures and trends. As can be seen in Figure 1(b), regional and local geological structures have been identified and modelled from observations in cored drillholes as well as underground. These include:

- Victoria Fault, which intersects the Dwarf and Fog lodes and strikes subparallel to the overall ore trend.

- Elizabeth Fault, which is also north-south trending, subparallel to the ore lodes and intersects the Mist and Whistle lodes.

- Mary Fault, which is located at the northern extent of the Mist orebody and is oblique to the strike of the orebody, however, parallel to the maximum horizontal principal stress. The Mary Fault also has numerous parallel splays that can be found at a distance of up to $50 \mathrm{~m}$ from the main fault, and can offset the orebody by up to $14 \mathrm{~m}$ to the east. The offset on the main Mary Fault is approximately $400 \mathrm{~m}$ dextrally.

- There are also several sub-vertical late stage quartz veins that crosscut east-west to the orebody and persist through multiple levels. These structures are more brittle than the host rock mass and often become seismically active when the mining front approaches them.

These discontinuities have the greatest influence on the rock mass response in low and high stress conditions. In low stress conditions, the loss of clamping force has the potential to create instability as the rock between discontinuities can become free to move and slide due to lost confinement. In high stress conditions, depending on their orientation in relation to the principal stress, the presence of these discontinuities may cause the structure to suddenly slip releasing energy in the form of a seismic wave. Consequently, "these waves are reflected at the excavation boundary, and stress changes result that may be sufficient to cause crack propagation, failure and massive ejection of rock" (Villaescusa 2014, p.338).

\section{$1.4 \quad$ Mining method}

Figure 2 shows a long section of the current Frog's Leg life-of-mine plan looking east. The mining method is longhole open stoping with cemented paste backfill, however, due to the variable orebody geometries, the extraction methodology and sequence have changed over the years to account for the orebody geometry, geotechnical constraints, recovery and productivity.

The upper part of the mine was extracted using longhole bench stoping progressing from top-down with central access retreat sequence. The inter-level spacing were designed at $20 \mathrm{~m}$ apart with the stope extraction leaving small island, rib and sill pillars that helped to control the rock mass deformation. There are two main sill pillars located at the 8200 and 8120 Levels in the Mist orebody and the 8160 and 8100 Levels in the Rocket orebody. 


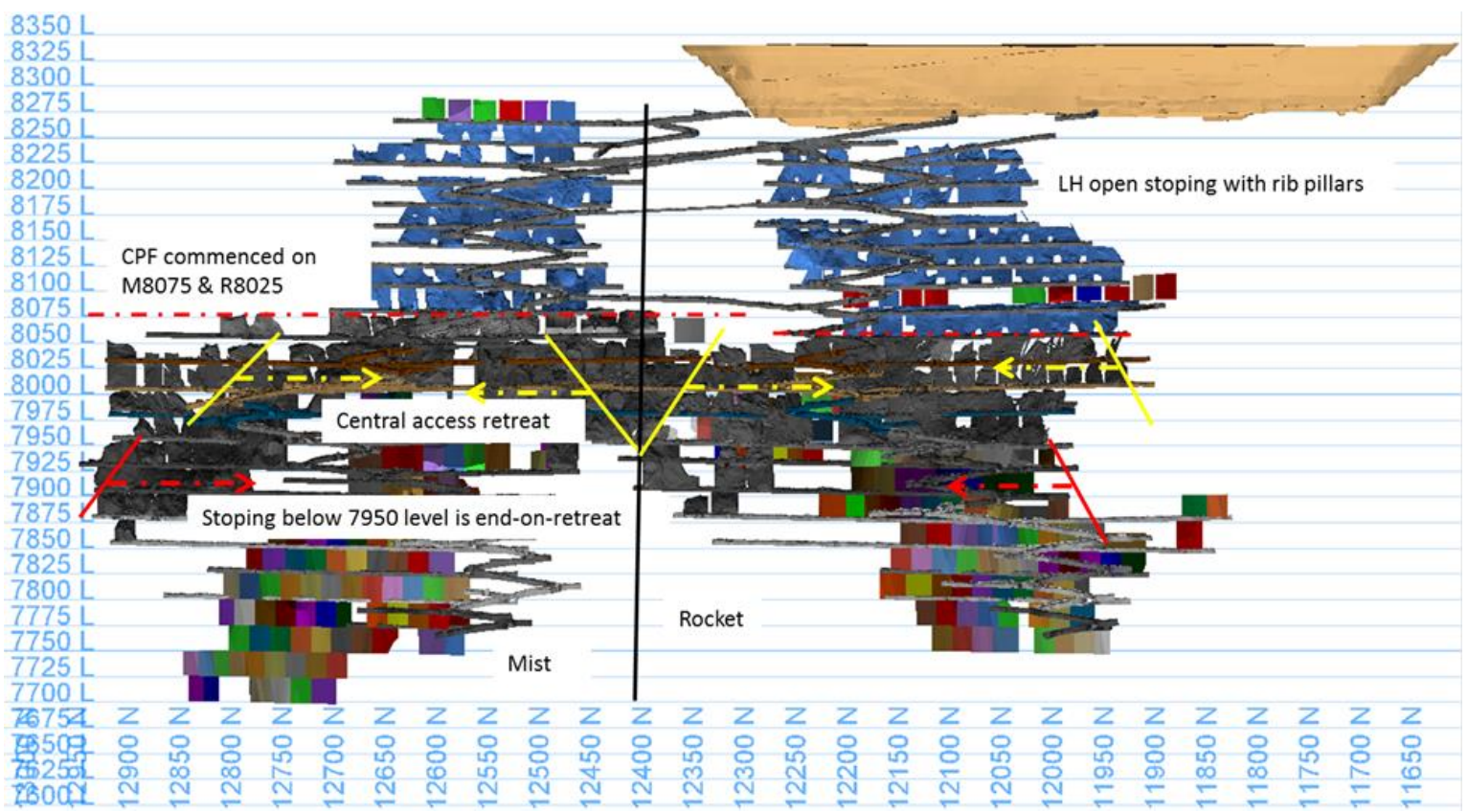

Figure 2 Frog's Leg underground mine stoping sequence (looking east)

The level accesses were developed to intersect the orebody in the centre and allow oredrives to be developed both north and south. The stopes were extracted retreating from north and south to the central access. These stopes were left without fill after extraction, although occasional campaign waste filling using uncemented rockfill was conducted in selected areas. Rib and sill pillars were designed to provide local and global rock mass stability.

Cemented paste fill was introduced at the 8075 Level in the Mist orebody, and at the 8025 Level in the Rocket orebody, to eliminate the need for leaving permanent ore pillars that provided the local and regional stability of the mined voids (Mgumbwa \& Nester 2014). The inter-level spacing was also changed from 20 to $25 \mathrm{~m}$ vertical distance with top-down central access retreat continuing to be the primary mining sequence. Stope backfilling assisted in managing ground stability by reducing the exposure of the mined voids, increasing ore recovery as well as enhancing flexibility of ore extraction strategy.

Below the 7950 Level an end-on retreat sequence was implemented, however, there was a remaining diminishing pillar between the 8000 and 7950 Levels. The following sections will only concentrate on the rock mass response during the extraction of the Mist orebody with the transition from central retreat to end-on retreat extraction sequence.

\subsection{Mist orebody extraction strategy}

At the dilation zone, where the orebody changes in dimension from narrow to greater than $20 \mathrm{~m}$ wide, two new technical and operational challenges emerged during the planning of the stope extraction strategy. First, the top-down extraction sequence relies heavily on the resulting paste fill strength and stability for horizontal paste fill exposures. However, the increased width of the ore lodes necessitated that the strength of the paste fill be increased to account for the wider horizontal paste fill exposure. For this to happen, either the cement content or the curing time had to be increased. Either of these two options had implications in terms of the operating costs and production schedule. Second, the wide southern Mist stopes delayed the sequence retreating from south to north as their turnaround time was considerably longer, thus, the northern stoping front moved faster than the southern stoping front.

Consequently new triple lift stopes were introduced in the dilation zone to account for the two challenges. The stopes in the southern stoping front were extracted as triple lifts retreating to the centre with the draw point being on the third level below. The shape of the stope crown was modified to minimise the horizontal paste exposure and to allow this paste to achieve a natural arch once it was exposed (Figure 3 ). 
Although the delayed sequence of stoping fronts retreating from south was not resolved, this option increased productivity while reducing the paste fill horizontal exposure.

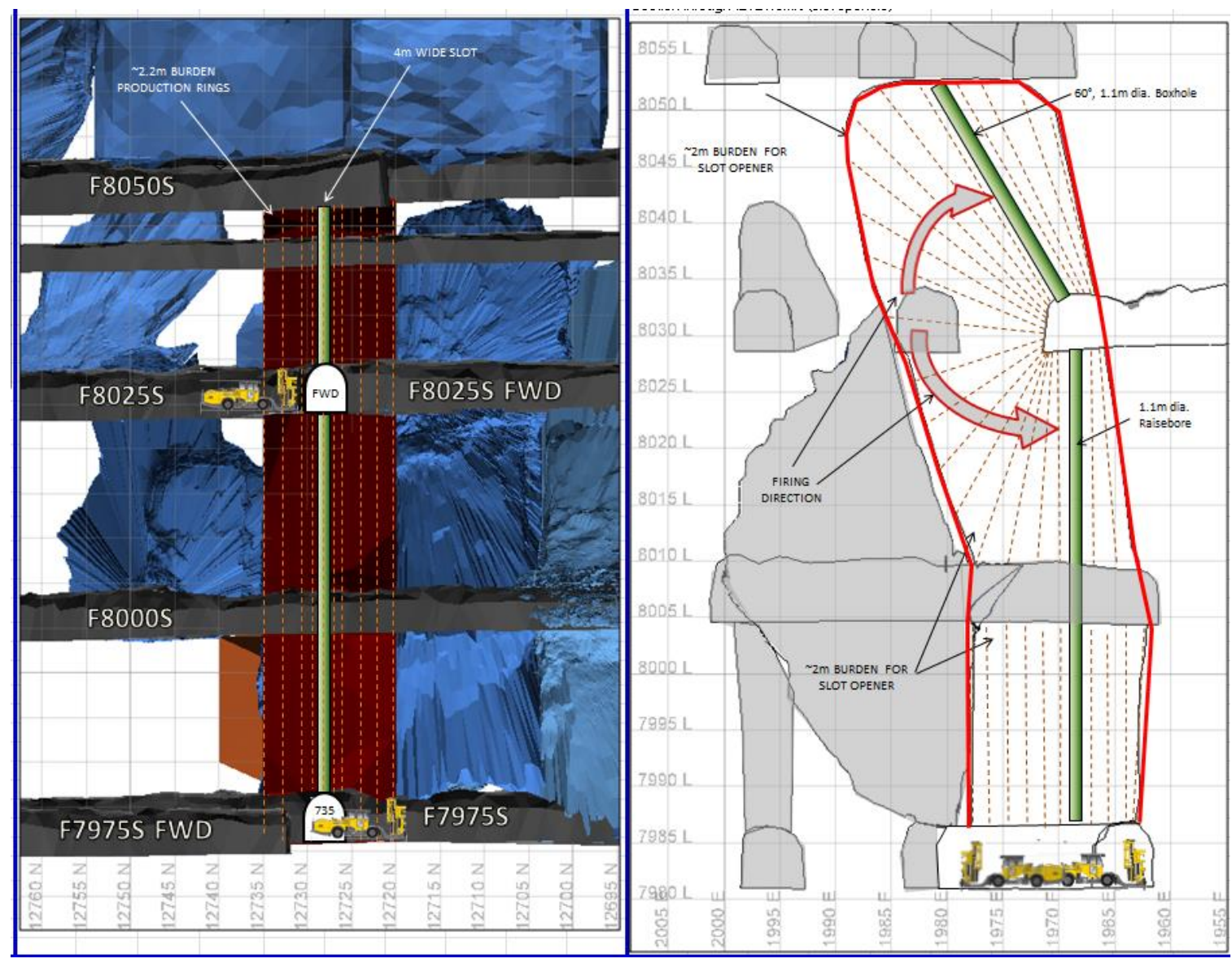

Figure 3 Triple lift stope arrangements (a) long section (b) cross-section with drill arrangement

\subsection{Geotechnical environment}

The Frog's Leg underground mine geotechnical environment is briefly described in the following sections.

\subsubsection{Rock mass conditions}

The rock mass at Frog's Leg mine is massive with relatively few joint sets; however, within the contact zone a variable weak unit of shale is present. The shale band is more predominant in the hanging wall than in the footwall and does not generate seismic activity as it yields under high loading conditions. Mikula (2016, p. 10) describes the impact of shale on seismicity as follows, "shales are patchy or variable in spatial extent, and at a small angle to the presumed stress field, resulting in situations where resistance to shearing along shales rests with non-shale bridges. Seismic rupture can then be envisaged". Thus, although shale does not accumulate energy due to early yielding under high stress conditions, this rock type may facilitate dynamic failure nearby.

The orezone is altered with quartz and carbonate infill in the joints and brecciation with extension fractures. The quartz rich rock, particularly in the ore zone, contains micro-fractures that are susceptible to further fracture under load. Rapid stress changes, particularly in the quartz rich ore development, tend to be subject to strainbursting. Table 1 shows the typical mean and standard deviation (SD) for intact rock properties and Table 2 summarises the mean rock mass $Q^{\prime}$ values. 
Table 1 Typical rock intact properties at the Frog's Leg underground mine

\begin{tabular}{|c|c|c|c|c|c|c|c|c|c|c|}
\hline \multirow[t]{2}{*}{ Rock type } & \multicolumn{2}{|c|}{$\begin{array}{l}\text { Young's } \\
\text { modulus } \\
(\mathrm{GPa})\end{array}$} & \multicolumn{2}{|c|}{$\begin{array}{l}\text { Poisson's } \\
\text { ratio }\end{array}$} & \multicolumn{2}{|c|}{$\begin{array}{l}\text { Density } \\
\left(\mathrm{kN} / \mathrm{m}^{3}\right)\end{array}$} & \multicolumn{2}{|l|}{$\begin{array}{l}\text { UCS } \\
\text { (MPa) }\end{array}$} & \multicolumn{2}{|l|}{$\begin{array}{l}\text { UTS } \\
\text { (MPa) }\end{array}$} \\
\hline & Mean & SD & Mean & SD & Mean & SD & Mean & SD & Mean & SD \\
\hline $\begin{array}{l}\text { Basalt } \\
\text { (hanging wall) }\end{array}$ & 73.4 & 3.8 & 0.26 & 0.14 & 28.9 & 0.6 & 133 & 50.3 & 11 & - \\
\hline $\begin{array}{l}\text { Shale } \\
\text { (hanging wall contact) }\end{array}$ & - & - & - & - & 28.8 & 1.5 & 99 & 55.6 & 15 & 3.6 \\
\hline $\begin{array}{l}\text { Ore } \\
\text { (altered basalt) }\end{array}$ & 65.9 & 15.3 & 0.12 & 0.08 & 28.8 & 1.2 & 115 & 52.4 & 18.5 & 4.9 \\
\hline $\begin{array}{l}\text { Ore } \\
\text { (quartz veins) }\end{array}$ & - & - & - & - & 26.2 & 0.9 & 145 & 9.2 & 9 & - \\
\hline $\begin{array}{l}\text { Volcanoclastics } \\
\text { (footwall) }\end{array}$ & 80.3 & 4 & 0.19 & 0.13 & 27.6 & 0.6 & 146 & 52.3 & 24 & - \\
\hline
\end{tabular}

Table 2 Mean Q' of various rock mass domains at Frog's Leg underground mine

\begin{tabular}{llll}
\hline Orebody & Hanging wall & Ore & Footwall \\
\hline $\begin{array}{l}\text { Fog } \\
\text { Mist }\end{array}$ & 38 & 37 & 29 \\
Rocket & 40 & 38 & 33 \\
Whistle & & 38 & 33 \\
Dwarf & 40 & & \\
Peron & & & \\
\hline
\end{tabular}

\subsubsection{Stress regime}

The in situ stress magnitude and orientation were estimated using an acoustic emission (AE) stress measurement technique described by Villaescusa et al. (2002). Three stress measurements were undertaken, with the latest one reported by Villaescusa and Machuca (2011) at approximately $414 \mathrm{~m}$ below the surface. The AE results were compared to other stress measurement results in the Kundana region and assessed to be reasonable. Table 3 shows the major principal stress magnitudes and directions as determined by the $A E$ technique. The orientation of the stress measurements have been validated underground by borehole breakout as well as failure observations in the oredrives.

Table 3 Summary of stress measurement results at Frog's Leg at $390 \mathrm{~m}$ below the surface

\begin{tabular}{lllll}
\hline $\begin{array}{l}\text { Principal } \\
\text { stress }\end{array}$ & $\begin{array}{l}\text { Magnitude } \\
(\mathrm{MPa})\end{array}$ & $\begin{array}{l}\text { Trend } \\
\left.\mathbf{(}^{\circ}\right)\end{array}$ & $\begin{array}{l}\text { Plunge } \\
\left(^{\circ}\right)\end{array}$ & $\begin{array}{l}\text { Stress gradient } \\
(\mathrm{MPa} / \mathrm{m})\end{array}$ \\
\hline$\sigma_{1}$ & 34 & 031 & 10 & 0.0870 \\
\hline$\sigma_{2}$ & 23 & 300 & 07 & 0.0588 \\
\hline$\sigma_{3}$ & 13 & 177 & 78 & 0.0332 \\
\hline
\end{tabular}




\subsubsection{Mining-induced seismicity}

Turner and Beck (2007) provide typical ranges where stress related fracturing around mining excavations in Western Australia starts becoming apparent; below $300 \mathrm{~m}$ in weaker rocks and below $600 \mathrm{~m}$ in stronger rocks. Frog's Leg started to experience these stress related challenges at a much shallower depth. Minor damage in oredrives, due to stress changes, became apparent around the 8075 Level, approximately $265 \mathrm{~m}$ below the surface. An Institute of Mine Seismology (IMS) seismic monitoring system comprising three triaxial sensors with natural frequency of 4.5 hertz $(\mathrm{Hz})$ was commissioned in September 2009 to identify areas in the mine in which seismicity accompanied rock mass failure. The system consisted of one Geophysical Seismometer (GS) data acquisition unit installed in the Mist orebody and one Network Seismological Processor (Net SP) data acquisition unit that was installed on the Rocket side.

Subsequent to the incidents described in this paper, the seismic monitoring system has been expanded, and currently consists of two GS data acquisition units, three Net SP data acquisition units, seven triaxial sensors (three with natural frequency of $4.5 \mathrm{~Hz}$ and four with natural frequency of $14.0 \mathrm{~Hz}$ ), and nine uniaxial sensors (two with natural frequency of $4.5 \mathrm{~Hz}$ and seven with natural frequency of $14.0 \mathrm{~Hz}$ ) located across the mine. A local magnitude $\left(\mathrm{M}_{\mathrm{L}}\right)$ scale is used to define the measure of the seismic event strength or size. The local magnitudes are calculated using the Hanks-Kanomori relation defined by Equation (1) (IMS 2015, p. 2).

$$
M_{L}=(2 / 3) \times \log P+0.92
$$

where:

$\mathrm{P} \quad=\quad$ is the potency.

The seismic system at Frog's Leg underground mine has been the key for identifying and locating seismic sources. To date, the most active seismic sources at Frog's Leg underground mine are:

- Closure or diminishing pillars.

- Geological structures that are mostly late stage quartz veins.

- Stress concentration in the abutments due to the stoping front.

- Mining in close proximity to the major faults (i.e. Mary, Mary Splay, Elizabeth and Victoria Faults).

Historically, the Mary Fault has been the most seismically active structure followed by the Mel and Kate structures. The Mary Fault tends to become seismically active when stoping or development is in close proximity, and the majority of significant large events have been associated with this structure. The maximum principal stress is subparallel to the Mary Fault and, when mining is carried out near this structure, the stress field imposes driving forces that can cause seismic slippage if the shear strength of this structure is exceeded. These large events would not necessarily be associated with blasting as they have occurred somewhat randomly.

Figure 4 shows the spatial location of seismic events $M_{L} \geq 0.5$ from January 2012 to July 2015. Figure 4(a) shows that all large events, indicated by red, are located in the Mary Fault or close to the Mary Fault. The Mel and Kate structures are located in the dilation zone towards the southern end of the Mist orebody. These structures were also seismically active during the extraction of the stopes between the 8050 Level down to 8000 Level (Figure 4 (b)). 


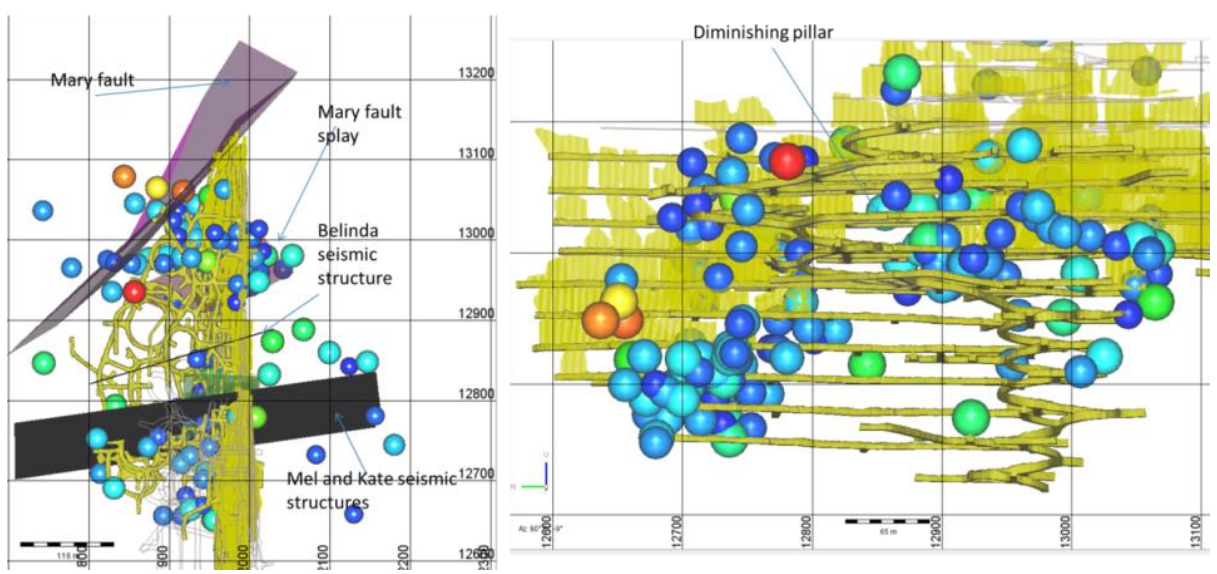

Figure 4 Spatial location of seismic activities at Frog's Leg underground mine for events $M_{L} \geq 0.5$ : (a) plan view indicating the active seismic structures; and, (b) long section looking east indicating the clusters of seismic activities

The majority of the seismically active structures are the late stage quartz veins, which are thin (range between 25 and $100 \mathrm{~mm}$ thickness), chloritic veneer, linear, persistent, and cross multiple levels of the mine. These structures are sub-vertical and crosscut the strike of the orebody running approximately east-west. Normally they are clamped by the principal stress that is oblique to these structures. However, as the extraction of the stopes approaches them, the clamping stress may be locally reduced allowing slippages. In some areas, the larger quartz veins (greater than $500 \mathrm{~mm}$ ) are prone to localised strainbursting and rock noise, as they are more brittle than the surrounding rock mass.

The stress abutment due to the stoping front has always been the major source of seismicity, particularly immediately after firing. This is mainly caused by the change in geometry of underground excavation due to the newly created mine void, which causes a re-distribution of stress within the mine. Usually the redistribution of stresses are within the stope abutment close to the newly created excavation, however, depending on the number of stopes open in adjacent levels, the redistribution can extend some distance away. The seismic hazard associated with this stress redistribution is reduced through re-entry exclusions. Figure 4(b) indicates the effect of the stoping front stress abutment on induced seismicity within the northern side of the mine; it is also compounded by the presence of the Mary Fault splays.

\section{$2 \quad$ Changing rock mass response to mining}

It is well known that "the response of a rock mass to a particular mining method reflects the mechanical and structural geological constitution of the orebody and the surrounding country rock" (Brady \& Brown 2004, p. 353). In situ stress magnitude and orientation determine the loading and the failure mechanisms of excavations. The combined effects of mining configuration (e.g. a diminishing pillar), complex geology and geomechanical properties, active seismic structures, high extraction ratio and increase in mining depth, cause changes in the rock mass response. The changes due to mining in the Mist orebody are described in the following sections.

\subsection{Changing mining-induced stresses}

The geotechnical problems with the Mist diminishing pillar were first observed during the extraction of the final central stope in the M8050 Level, which was approximately $290 \mathrm{~m}$ below the surface. Underground observations indicated that the final stopes within the central pillar suffered the following instability issues:

- Large fracture depth at large span access intersections and the potential formation of a release plane at the ore and waste contact.

- High stress concentration in the pillar causing increased seismic activity. 
- Rapid loss of compressional (confining) force in pillars and abutments of a critical strike length leading to failure depths exceeding the support element lengths.

In order to manage these geotechnical issues, the mining sequence was changed from a top-down central access retreat sequence to a top-down end-access en echelon pillarless retreat sequence. However, during this time, the infrastructure and ore development had already progressed below the 7925 Level. The change in mining sequence was only possible below the 7950 Level.

It was recognised that until the transition was complete, unfavourable mining geometries would attract high stress concentrations in the final pillar. The central access, coupled with the multiple ore lodes, led to four way intersections being created to allow access to the footwall ore lodes. With the increased extraction ratio, the mine became more vulnerable to stress damage, especially as the diminishing pillar retreated towards these intersections.

As the mine progressed, the operation became more and more susceptible to stress related problems. Therefore, during the extraction of the diminishing pillar, operational rules of thumb were established to reduce personnel exposure to potentially compromised ground conditions. These rules of thumb were developed based on monitoring, stress modelling, underground observations and experience. It was recognised that the final $50 \mathrm{~m}$ strike incorporating the diminishing pillar could become inaccessible due to unmanageable ground conditions and, therefore, be deemed non-entry. Stopes located within the diminishing pillar were extracted as double or triple lift stopes, with the lower extraction level having a sufficient pillar size to ensure it had not been compromised. Production drilling and charging activities in the diminishing pillar were conducted from an adjacent hanging wall drive that was developed specifically for this purpose.

\subsection{Changing seismic response}

The change in rock mass response, as manifested by the increase in number of larger seismic events, has been cyclic at Frog's Leg underground mine since 2013. The diminishing pillar between the 8050 and 7975 Levels was extracted between May 2013 and November 2014. This pillar was partly in a stress shadow as the Mist lode, between the 8050 and 8000 Levels, was already extracted and paste filled. The majority of the large seismic events recorded during the extraction of this diminishing pillar were associated with the Mary Fault and the Mel and Kate structures.

Figure 5 shows the magnitude-time history graph for events $M_{L} \geq 0.5$, and incorporates the cumulative number of large events, between January 2012 and February 2016. The magnitude-time history analysis (how magnitude varies over time) of clusters of seismic events provides valuable insight into seismic hazard. A significant change in the number of large events was noticed towards the end of 2014. During this period, the M7925NOD was being developed in preparation for triple lift stopes in the diminishing pillar. Due to this noticeable change, the ground support in the M7925NOD was changed from normal split sets and mesh, to incorporate fibrecrete floor-to-floor over the mesh. Also, ground support in the M7950 Level was upgraded in preparation for the extraction of the final diminishing pillar. This ground support upgrade included resin D-bolts in the hanging wall drive, fibrecrete floor-to-floor over the mesh as well as cable bolting in the F7950SOD, and Kinloc bolts in the M7950SOD. 


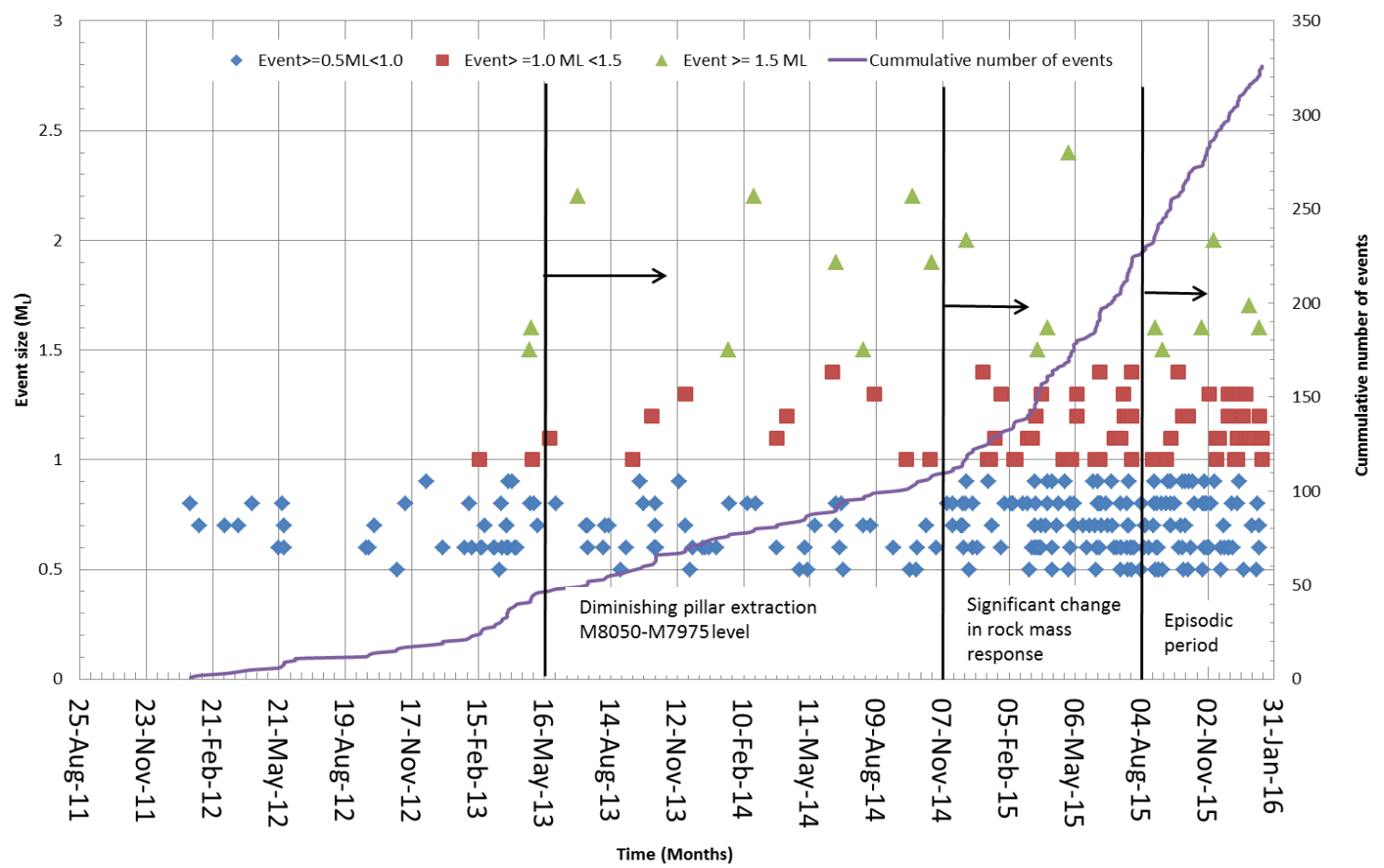

Figure 5 Events time history and the cumulative number of events $M_{L} \geq 0.5$ for a period from January 2012 to January 2016

By March 2015, there was a significant increase in the rate of large events. The reduction in pillar size as stope extraction retreated from both the north and south resulted in increased stress and seismicity. The bulk of the high grade ore at Frog's Leg underground mines comes from the Mist orebody, with stopes from the north stoping fronts contributing the majority of the high grade ore tonnes produced. Simser (2007, p. 437) states, "the mining sequence is one of the most important factors dictating ground performance, although pressure to get development in place and then changes in the mine plan can create non-ideal situations". A non-ideal situation was created between the M/F7925 Level and the M/F7950 Level during the transition from a top-down central access to a top-down end-on en echelon retreat sequence. As the extraction of the Mist diminishing pillar progressed there was a significant increase in seismicity as well as rockbursting.

\subsection{Seismic damage}

The following cases describe the two major rockbursts that led to a temporary halt in production activities in the Mist orebody pending the development of new extraction and ground support strategies. The case studies will examine the main contributing factors, failure mechanisms and ground support performance during the rockbursts.

\subsubsection{Rockburst damage in the M7925NOD}

The rockburst in the M7925NOD was the first major rockburst at Frog's Leg underground mine located in an oredrive. This rockburst was caused by a $\mathrm{M} \mathrm{L} 2.0$ seismic event with the monitored location approximately $10 \mathrm{~m}$ from the failure zone, in the pillar between the M7925NOD and the F7925NOD. The event occurred on 10 November 2015 at 19:44:01 and was not temporally associated with any stope or development firing.

Approximately 200 tonnes of rock were dislodged from the right hand shoulder of the oredrive as a result of the shakedown from the seismic event. The fall of ground area was approximately $10 \mathrm{~mL} \times 3.5 \mathrm{~m} \mathrm{~W} \times 3.2 \mathrm{~m} \mathrm{H}$ with the damaged area extending up to $50 \mathrm{~m}$ from the main fall of ground. The damage was considered to be ejection of the right hand wall and shakedown from the backs, bounded by the two observed geological structures. As can be seen in Figure 6(a), the ejected material consisted of relatively small fragments of rock, with larger slabs of dislodged fibrecrete. The damage to the right hand 
shoulder of the drive in the areas leading up to the rockburst location was due to excessive deformation of the rock mass under dynamic conditions. It should be noted that fibrecrete is brittle in nature and it cannot sustain excessive deformation under dynamic loading. This was evident from the way the fibrecrete over mesh failed through buckling in the shoulders, as seen in Figure 6(b).
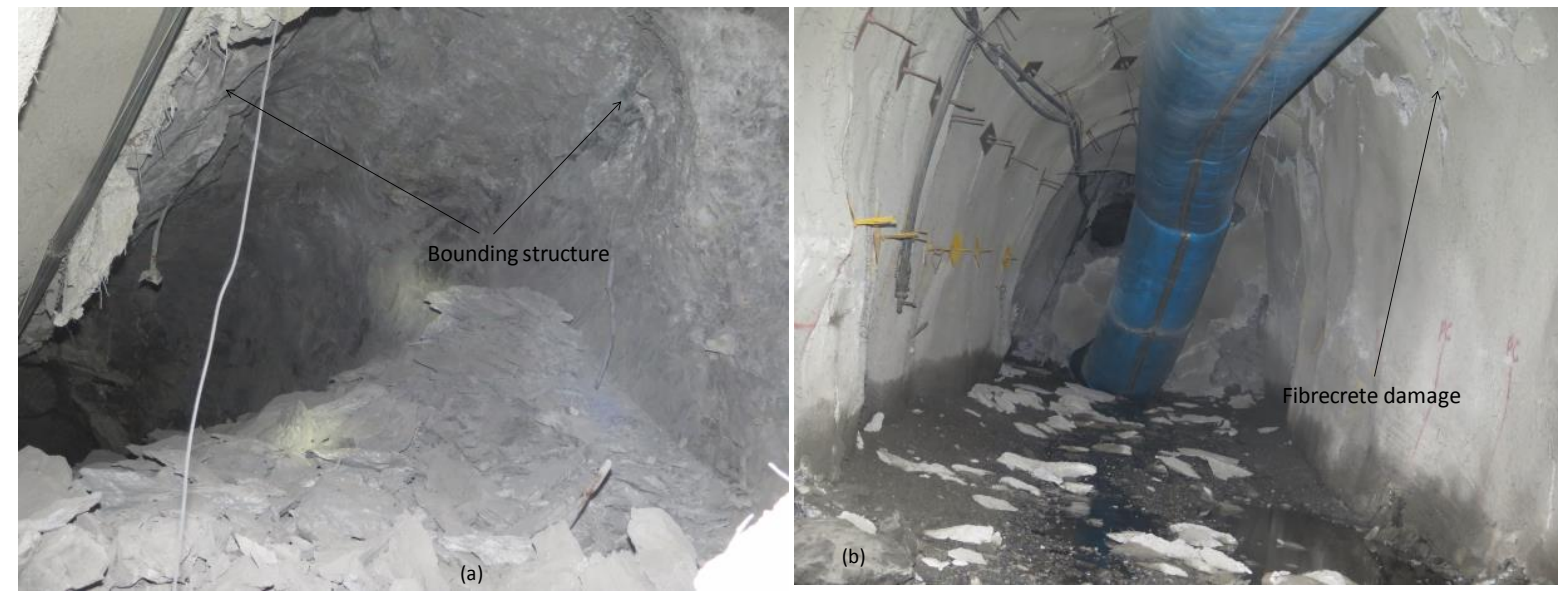

Figure 6 Rockburst damage in the M7925NOD: (a) view of the fall of ground with two bounding structures; and, (b) view from $30 \mathrm{~m}$ leading to the fall of ground indicating the damage to fibrecrete in the shoulders

Figure 6(a) also indicates two planar structures dipping towards the east and subparallel to the oredrive. These two structures are the Elizabeth and Victoria faults, which intersect in the lower levels as the two subparallel lodes, Mist and Fog, become one. Several late stage crosscutting structures were also identified in this area, including the Belinda structure that was also located very close to the failure zone.

The Victoria and Elizabeth faults formed a wedge, with an apex well above the embedment length of the installed ground support, composed of split sets. Due to the complex stress distribution in the diminishing pillar, it is likely that these structures sheared, causing this large event.

Following detailed underground observations along with the seismic data analysis, it was concluded that, the most likely failure mechanism was slip along the two major faults, the Elizabeth and Victoria faults. The presence of several late stage quartz veins complicated the stress change in the area. It was noted that the stress change would have been gradual due to the initial size of the pillar, however, as multiple blasts occurred in the M7925N_883 stope, potentially deformation could have occurred causing slip along these structures.

The M7925NOD was a relatively new drive that was parallel to the F7925NOD creating a $9 \mathrm{~m}$ pillar between the two oredrives. The primary ground support units in this area consisted of $2.4 \mathrm{~m}$ long split set, mesh and fibrecrete. An upgrade of ground support was also conducted in the area directly to the south of the M7925N_883 stope brow for a distance of $25 \mathrm{~m}$ along the oredrive prior to the start of the extraction of this stope. The upgrade of ground supports consisted of $2.4 \mathrm{~m}$ long Kinloc bolts and mesh to cover the fibrecrete. The $25 \mathrm{~m}$ strike length ground support upgrade was based on previous mine experience and underground observations where ground deterioration, due to stress abutments, occurred within $20 \mathrm{~m}$ from the stope brows.

No ground supports upgrade was conducted in the damaged area including at the fall of ground, as the area was beyond the $20 \mathrm{~m}$ zone defining the high stress abutment. A higher depth of failure was also noted due to the two structures forming a wedge; the existing ground support did not have sufficient embedment length to contain the wedge that was formed between the two structures.

Following this rockburst, Frog's Leg began investigating the use of quad stopes (four levels) to extract the diminishing pillar as a way of limiting personnel exposure. 


\subsubsection{Rockburst in the F7875N_880_secondary stockpile}

The rockburst in the F7875N_880 secondary stockpile was the second major rockburst to occur at Frog's Leg underground mine. The rockburst occurred on 11 January 2016 due to a M 1.6 seismic event with the monitored location $10 \mathrm{~m}$ in the footwall of the drive, directly below the F7875N_880 secondary stockpile. The event occurred at 05:38:39 directly after the firing of the F7900N_900 and the M7925N_883 stopes. The event was associated with the stress change experienced when the two stopes directly above the F7875N_880_SSP were blasted. An aftershock event of $M_{\llcorner} 1.2$ occurred at 05:39:34 and was located in the F7900NOD.

The main event and the aftershocks all occurred inside the prescribed exclusion zones and times. No underground personnel were exposed to the elevated seismic hazard experienced during the blasting time as a 12 hour seismic exclusion time was imposed prior to the firing of the stopes. Both events were felt on the surface, therefore, a further restriction was issued by the geotechnical department to ensure that a geotechnical inspection was conducted after the seismic re-entry period was lifted, and before any other underground personnel were allowed to access the seismic exclusion levels.

This underground inspection revealed minor damage in the F7900NOD at the stope brow, and major damage in the F7875NOD. This major damage involved approximately 300 tonnes of rock mass being ejected in an area approximating $45 \mathrm{~m}^{2}$ at an average failure depth of $2.6 \mathrm{~m}$. Figure 7 shows the damage was constrained to the bullnose between the secondary stockpile and the oredrive wall, as well as the shoulders in the oredrive. Underground observations indicated the mechanisms of rockburst damage were a combination of bulking due to the repeated dynamic loading and the ejection. As can be seen from Figure 7(b), the rock mass was ejected and thrown $5 \mathrm{~m}$ from the bullnose pillar and arrested by the left hand wall of the oredrive. Underground observation, before the rockburst, indicated the pillar was under high load due to the abutment stress from the stoping fronts with the secondary stockpile creating an additional degree of freedom for the rock mass to displace. The characteristics of the broken muckpile from the ejected rock mass were in the form of small plate like pieces, which confirm the stress fracture failure mechanism.

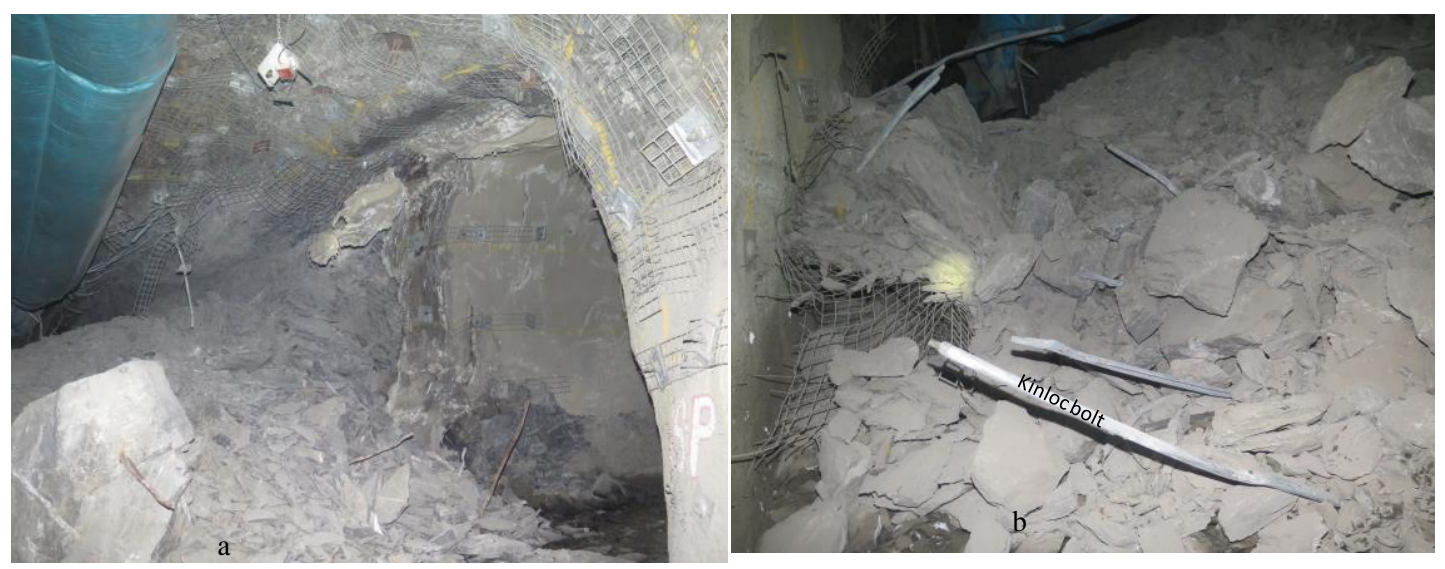

Figure 7 Rockburst damage in the F7875N_880 secondary stockpile: (a) damage extent in the bullnose pillar; and, (b) characteristics of the ejected rock mass

The installed ground support in this area was split sets and mesh as the primary support installed during the oredrive development and campaign fibrecrete to grade line without mesh. The intersection at the secondary stockpile had twin strand cables bolts installed as a standard. Due to increased seismicity in the Mist orebody, an upgrade of the ground support, by adding Kinloc bolts and mesh straps, was completed to a distance of $100 \mathrm{~m}$ ahead of the retreating stoping fronts.

Despite this ground support upgrade, the ground support could not control the rock mass movement during the seismic event. The rockburst completely destroyed the existing ground support systems in the right hand wall, shoulder and the bullnose between the F7875N_880 secondary stockpile and the F7875N_925 stope paste wall. The support strategy employed at the pillar involved strapping the pillar 
from grade line and above as it was recognised that the pillar was vulnerable to stress damage. The failed mass in the pillar was approximately $3.3 \mathrm{~m}$ in depth and the fracture depth reduced to $0.5 \mathrm{~m}$ in the backs. The dog-leg shape of the Kinloc bolts (Figure 7(b)) provides an indication of how the bolts were deformed during the dynamic movement.

The cable bolts in the backs at the intersections contained the failure, although these cables were significantly loaded with the plates bending. The mesh was also bagged, indicating some broken ground resulted after the seismic events. The intersection had a smaller depth of failure compared to the pillar, and the fact that Kinloc bolts and straps were installed in the intersection, in addition to cables bolts, had a positive effect on the dynamic load capability of the ground support system in the intersection.

\section{Management of changing rock mass conditions}

Following the second significant rockburst in January 2016, a decision was made by mine management to temporarily suspend mining in the Mist orebody until a review of the current extraction and ground support strategy had been undertaken.

\subsection{Geotechnical Review Board}

A Geotechnical Review Board (GRB) was formed following the significant rockburst damage that occurred on 11 January 2016. As previously discussed, this event was preceded by a $M_{L} 2.0$ on 11 November 2015, which also caused significant damage. The GRB consisted of three highly experienced geotechnical consultants with relevant experience in Western Australian mining industry. The GRB workshop also involved in-house technical staff, mine management and corporate technical staff. The review was undertaken over three days and included underground investigations, background presentations and detailed discussions.

The following is the outline of the aims of the review (Dunn 2016, p. 1):

- Requirement to re-open the Mist orebody with the first priority being the F7900 level, as this level was the key extraction level for the planned diminishing pillar stoping.

- Assessment of the proposed mining sequence going forward, discussion of general sequencing rules and the consequences of using the diminishing pillar sequence.

- The ground support design methodologies.

- The input parameters in the ground support design.

- Recommendations on rockbolts and surface support elements.

- Additional data capture and analysis.

The following were the main outcomes from the GRB:

- Revised extraction sequence required. An attempt to extract the diminishing pillar with a top down en echelon extraction sequence, as the proposed quad lift sequence is likely to result in an unfavourable seismic response. This would require access to be re-established to the 7975 and 7950 Levels, and stopes from these levels to be extracted as single lift stopes.

- Upgraded dynamic ground support is required $50 \mathrm{~m}$ ahead of the stoping front on the access level and on the level below, as well as in vulnerable areas such as intersections with structures.

- Ground support design:

- Apply a range of design methods as well as consider what neighbouring mines are using as inputs.

- Deeper ground support (6 $\mathrm{m}$ long) required to account for observed failures $>3 \mathrm{~m}$. 
- Kinloc bolts not considered as suitable ground support for these dynamic conditions.

- Endorsement of intent to use appropriate dynamic bolts that have a proven track record in the industry.

- Improve connection between surface support and rockbolts should be investigated.

- The use of fibrecrete was endorsed; the application of mesh over the fibrecrete would be required in some areas.

- Upgrading of seismic monitoring system is endorsed; careful quality control and assessment of the seismic event locations is required.

- Seismic monitoring is an important component of seismic hazard assessment and risk management through re-entry times following firings and large events.

- Continue with and improve data collection from large seismic events (damaging and non-damaging); include assessments of ground support performance, information on blasting as well as more observational data.

It was also noted that the design of ground support for dynamic conditions is still a grey area. An industry accepted ground support design methodology, as outlined in the Canadian Rockburst Support Handbook (Kaiser et al. 1996), is applied at Frog's Leg. This method depends on various assumptions and is difficult to apply with confidence.

The GRB, however, could not provide a definite answer on the design approach, although it was noted that an empirical approach similar to that developed by Mikula (2012) could be adopted and developed at Frog's Leg. However, at the time, Frog's Leg had only two data points with significant damage and depth of dynamic failure that is needed for the empirical approach, and for the Canadian Rockburst Support Handbook (Kaiser et al. 1996) method. These two data points were insufficient to develop a site specific design chart, as proposed by Mikula (2012), therefore, more data was required to develop site specific values as inputs into ground support design calculations.

\subsection{Revised extraction strategy}

After the $M_{L} 2.0$ seismic event and associated rockburst in the M7925NOD in November 2015, a series of options were investigated on how to safely extract the remaining diminishing pillar from the M7925NOD to the M8000 Level. Several technical meetings were held onsite to evaluate various options in terms of safety, productivity, cost and the impact to the overall mining sequence in the Mist orebody. The decision was made to extract the remaining diminishing pillar as quad lift stopes with draw points on the 7900 Level. This option was in its final stage of planning when the second rockburst occurred in January 2016. However, the proposed quad lift extraction strategy was considered not optimal by the GRB due to the following reasons:

- It would create a remnant at the top of the stope due to the stope firing sequence being bottom-up, further isolating the remaining ground. This could again become the source of seismicity as this remnant pillar would continue to be loaded.

- It results in the progressive shrinking of an isolated rib pillar that can suddenly yield resulting in a large seismic event.

- Possible caving of the stope hanging wall due to the presence of a shale contact.

- Large end wall and horizontal paste fill exposures will be created which are likely to experience instability and create extraction issues for adjacent stopes.

The quad lift sequence was also likely to result in an unfavourable seismic response, due to the presence of several seismically active structures within an unfavourable geometry. A new extraction sequence that would better manage the diminishing pillar was to be investigated. Ideally, the top-down en echelon sequencing of stopes in the central pillar was to be adopted, if access in the 7975 Level was permitted. This 
sequence would result in early extraction of the yielded pillars on the 7975 Level, pushing the stress down to the 7950 Level and allow the rock mass to yield on this level while extracting the stopes in the 7975 Level. The top-down mining sequence would also avoid a high stress concentration in the diminishing pillar by creating a favourable mining geometry through a newly established en echelon sequence.

Figure 8 shows various sequence options that were investigated for the proposed top-down en echelon stoping sequence involving single lifting starting in the 7975 Level. The numbers indicate the options that were considered with the top number indicating the first option and the bottom number indicating the second option. Due to the geometrical configuration of the oredrives and infrastructure in the M7925 Level, it was concluded that access through this level would be challenging. Therefore, the stopes between the 7950 through to the 7900 Level were planned as double lift stopes. These stopes are outside the true diminishing pillar, which is between the 7950 and the 8000 Levels. It was also concluded that the hazards associated with the quad lift stopes are less likely to be encountered with double lift stopes. As experience at Frog's Leg indicates, there have been no significant issues with double lift stopes.

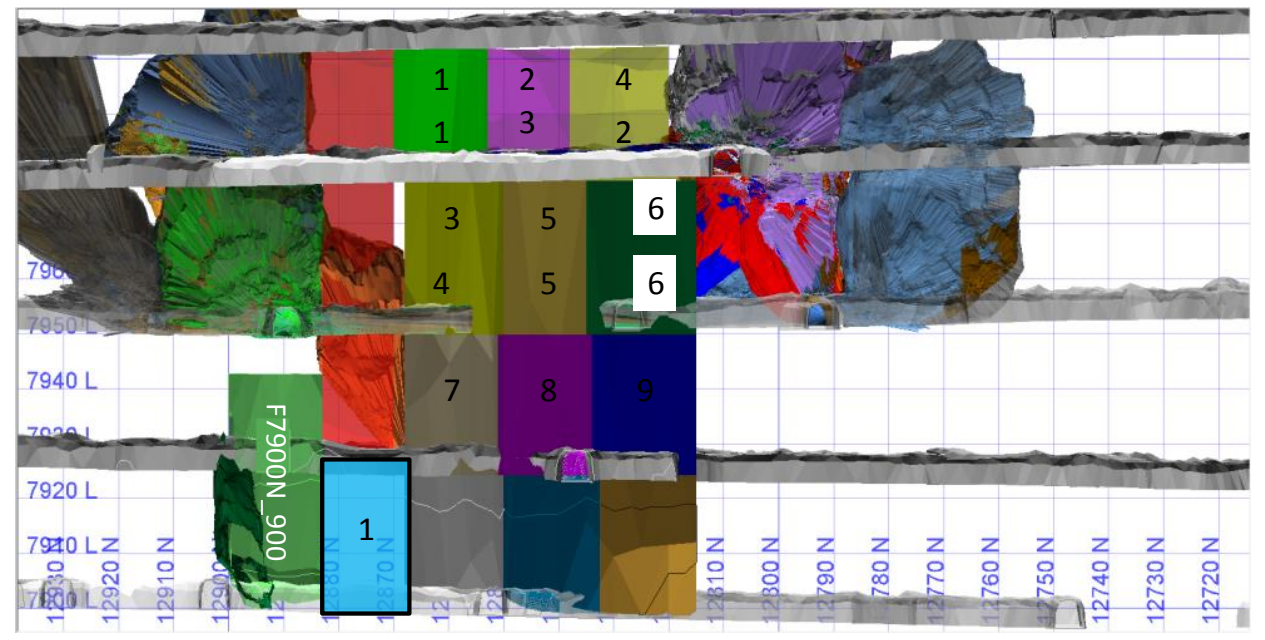

Figure 8 Options for the extraction of the diminishing pillar

As part of the geotechnical assessment, elastic numerical modelling using Map3D version 65 (Map3D International Ltd 2017) was conducted for the proposed mining sequence to identify potential stress problems that may be encountered during the extraction. The aim of the modelling was to compare these options based on known ground conditions in the excavations (Human 2016a).

In addition to numerical modelling of the diminishing pillar, it was also recommended that a review of seismicity in the diminishing pillar, particularly in the 7975 Level, be conducted. The review mainly considered the period of seismic activity between August 2015 and February 2016. Figure 9 shows the seismic events $M_{L} \geq 0.0$ recorded during this period. The events cluster in an oval shape at least two stopes ahead of the current stoping front. For the diminishing pillar, the bulk of these events are located below the M7975 Level where the stress concentration is positioned. Although the core of the pillar would still be carrying load, the major part of the pillar is likely to be yielded in and above the 7975 Level. 


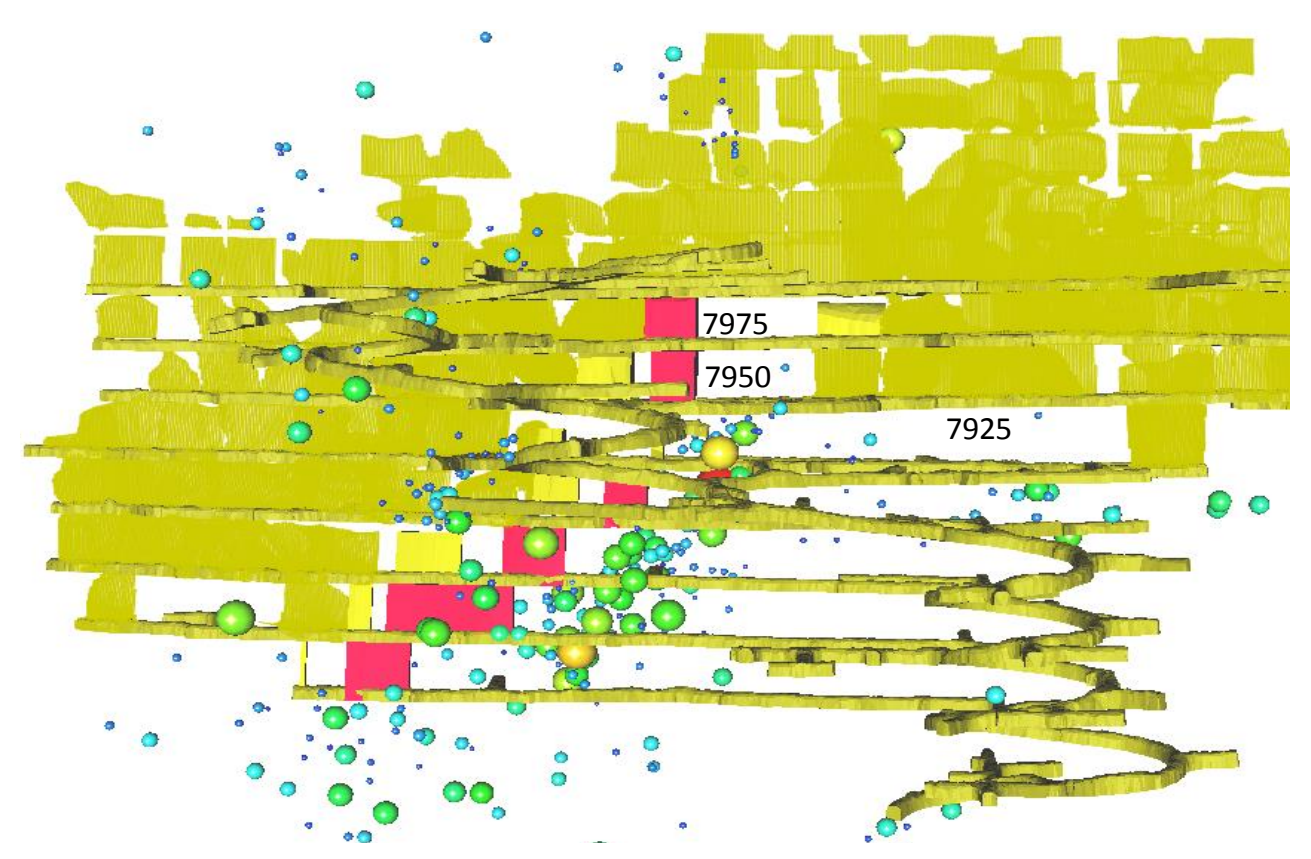

Figure 9 Seismic events $M_{L} \geq 0.0$ in the Mist stoping front and the diminishing pillar from August 2015 to February 2016

\subsection{Ground support design and upgrade}

Based on observed extent of damage from the rockbursts, it was recommended that an upgrade of dynamically capable ground support was required for at least $50 \mathrm{~m}$ ahead of the current stoping fronts, on any active level, and one level below. This would include vulnerable areas such as wide spans, intersections or areas that are intersected by a fault. The length of ground support elements had to be increased to ensure anchorage outside the damage zone as the depth of failure was found to exceed the length of the ground support elements used at the time.

The design of ground support systems subjected to dynamic loading was considered and reviewed by the GRB. Langille (2016) noted that the design of rockburst resistant support is still not a well-defined science, with empirical tools requiring numerous data points to increase confidence, while the kinetic energy method is also limited.

Consequently, the design of ground support was based on conservative input parameters to cater for a range of loading conditions and included the following:

- The design event magnitude was based on a statistical seismic hazard assessment undertaken by Institute of Mine Seismology (2015).

- The source location of the design event was based on recent observations of high energy seismic events, with monitored locations approximately $10 \mathrm{~m}$ away from the damage area.

- Institute of Mine Seismology (2016) developed a site specific ground motion prediction equation to estimate peak particle velocities in solid media.

- A site amplification factor of three was assumed and applied to the ground motion prediction.

- The depth of failure was based on underground observations and also investigations from the broken ground in the oredrive during cable bolt and production drilling. The two major rockbursts had a depth of failure greater than $2.5 \mathrm{~m}$, however, based on underground observations, it was concluded that, a depth of failure of $1.5 \mathrm{~m}$ was a more realistic estimate for the mine.

The required energy absorption was assessed based on these inputs and a Factor of Safety was then calculated for a variety of ground support systems and upgrades (Human 2016b). In addition, various 
ground support options were investigated to identify currently available dynamic-capable ground support systems on the market. The key requirement of these ground support systems was:

- The load and deformation capacity.

- Proven technology meaning the ground support is being used successfully somewhere else in similar environments.

- Embedment length of the reinforcement element.

- Ease of installation using standard jumbo procedure.

- The supply and logistic issues as these bolts would be required immediately.

The chosen rockbolts were to be integrated fully with the surface support systems. The introduction of in-cycle fibrecrete combined with mesh over the shotcrete was endorsed as it would enhance the level of surface support. In a new development, $2.4 \mathrm{~m}$ long resin dynamic bolts were proposed as these areas have limited wall damage and are unlikely to have resin encapsulation issues. Based on experience from other sites, Garford dynamic resin bolts and $6 \mathrm{~m}$ Garford dynamic cablebolts were selected as the main dynamic capable reinforcement system. Conventional split sets, stiff split sets (grouted) and Kinloc bolts were to be continued to be used in areas where squeezing conditions are likely to occur.

\subsection{Seismic monitoring system}

Subsequent to the two rockbursts and the GRB, the seismic monitoring system was upgraded. The seismic monitoring system enables geotechnical personnel to assess the location, magnitude and other source parameters of seismic events. The data processing and software maintenance is provided in 'real time' by IMS, with monthly reporting. On a daily basis, the diurnal distribution of seismic events is used to assess the standard re-entry period after production blasting. Figure 10 shows the diurnal chart for the Mist orebody, including the diminishing pillar. There is a strong relationship of events to blasting, and a 12 to 24 hour time window for seismic activity to decay to background level. The decay rate is influenced by the number of open stopes in close proximity to each other, the induced stress abutment due to the stoping front, and the presence of active geological structures. The large seismic events outside the blasting time indicate that most of these events are not temporally associated to the stress changes due to blasting.
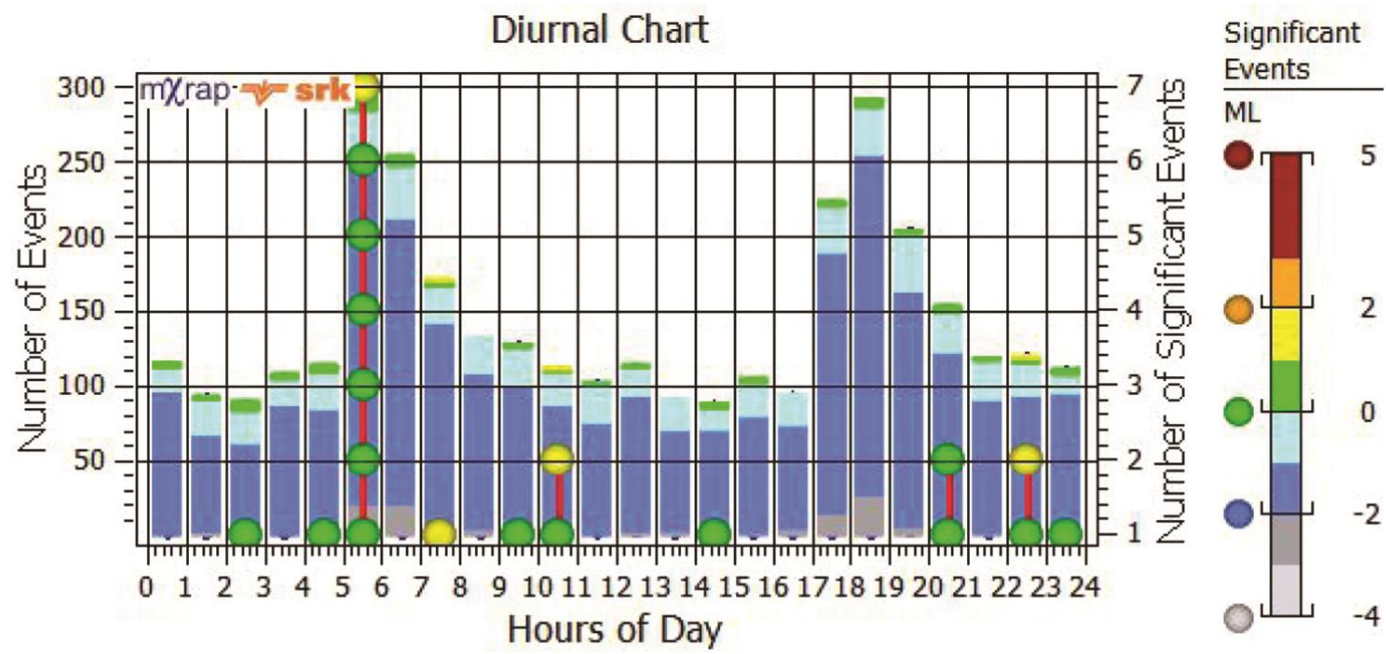

Figure 10 Diurnal analyses for seismic events in the Mist orebody including the diminishing pillar

\section{$4 \quad$ Progress to date}

Much work has been completed to refine the extraction sequence in the diminishing pillar as well as the ground support upgrade. 
The revised extraction sequence in the diminishing pillar incorporates single lift stopes accessed by transverse crosscut developed in the M7975 Level from the hanging wall drive. The first stope to be extracted, the F7975N_870 stope, was from the northern upper corner of the diminishing pillar. The development of the transverse crosscut, the F7975N_870 XC, was completed with a few geotechnical challenges as the development crossed the paste filled oredrive. These areas had more broken ground, mainly due to stress as well as water flowing through the contact. The ground support in this area involved in-cycle fibrecrete, mesh and Kinloc bolts as primary support, followed by Garford dynamic cables. Kinloc bolts were used mainly because resin bolts could not be installed in the broken ground.

The stope design was completed in line with the crosscut development design as per stope design procedures. Figure 11 shows the planned extraction methodology for the F7975N_870 stope, which was the first stope (refer to Figure 8) in the diminishing pillar. This stope was planned to incorporate firing the sky slot drilled in the M7975N_870 XC as the first firing, then slash firing down into the crosscut that was to be drilled from the M8000_FWD to increase the void. The mass firing was drilled from the M8000_FWD due to the perceived risk in the M7975 Level. This stope was extracted successfully without any major geotechnical issues and has since been paste filled.

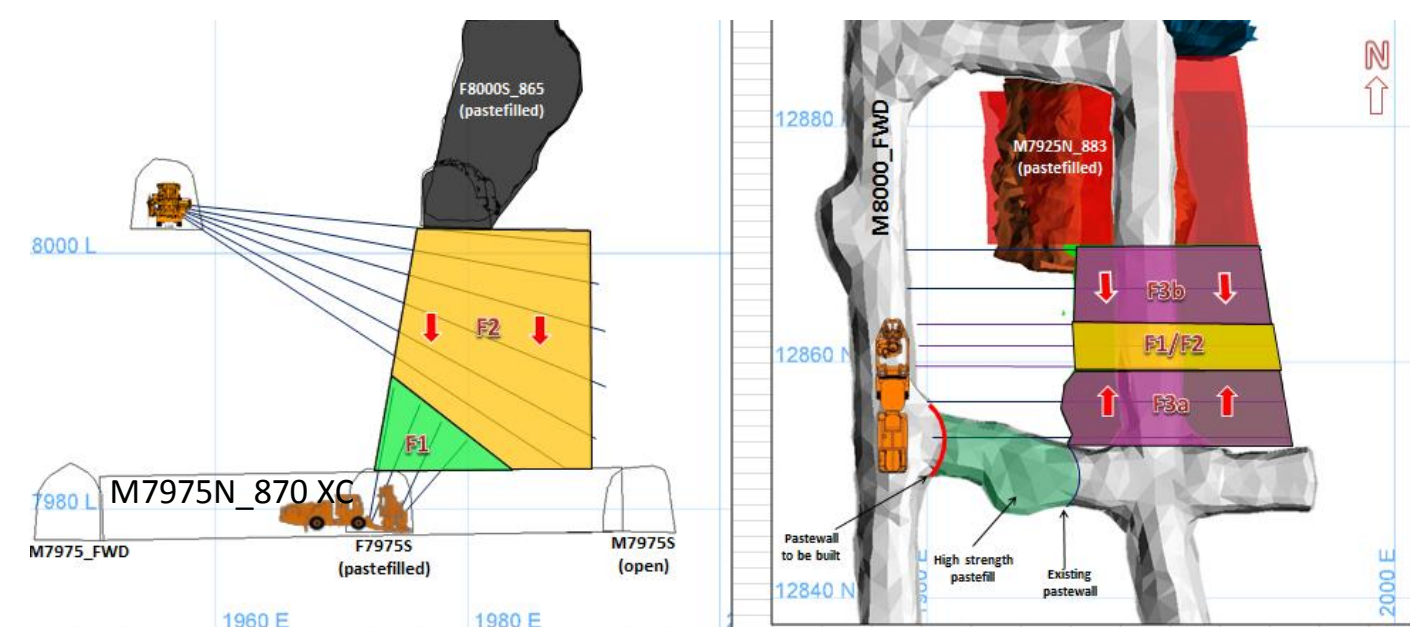

Figure 11 F7975N_870 stope extraction methodology

The seismic response during stope firing was mainly constrained to an area between the 7950 and the 7900 Levels. The diminishing pillar in the 7975 Level did not respond seismically; a few moderately (i.e. $M_{L}<1.0$ ) large events were also experienced in the M8000 Level and the decline. Subsequent geotechnical investigation, along with underground mapping, indicated some seismically active structures that intersect the diminishing pillar also crossed the M8000 Level and the decline. Following these observations, ground support upgrades comprising Garford resin bolts and Garford dynamic cables were installed in the area of M8000 Level and the decline.

The ground support upgrade required to comply with the GRB recommendations has been successfully implemented. Initially, problems were experienced with the supply of the $6.5 \mathrm{~m}$ dynamic cable bolts, but this issue was resolved.

Initially, the focus was to upgrade the ground support to comply with the GRB recommendations for the first $50 \mathrm{~m}$ back from the stoping front on each production level and the level below. However, the extraction of the diminishing pillar has been slow; delaying the extraction sequence in the Mist orebody. This has provided an opportunity to finish all the ground support upgrades required on all levels.

\section{$5 \quad$ Concluding remarks}

A significant increase in seismicity, including two significant rockbursts was experienced at Frog's Leg underground mine between August 2015 and January 2016. During this period, the mine was in transition from a top-down central access retreat sequence to a top-down end-on en echelon stoping sequence. The 
increased stress due to the increasing mining depth, higher extraction ratio, unfavourable mining geometry caused by the diminishing pillar and some seismically active crosscutting structures were found to be the main contributing factors to this unfavourable response.

Given the higher seismic hazard associated with the diminishing pillar due to high induced stresses, a triple lift stope extraction methodology, which eliminated the exposure of personnel and equipment to potentially unstable rock mass conditions was initially implemented. All production activities in the triple lift stope were planned to be conducted outside the oredrive from the hanging wall.

Although the previous extractions of diminishing pillars, using triple lift stope methodology, had been successful in the Mist orebody, the final diminishing pillar encountered significant challenges that involved seismicity and rockbursting. Two major rockburst events occurred as the extraction of the first triple lift stope in the diminishing pillar commenced.

Following the first rockburst, the possibility of extracting the diminishing pillar using a quad lift was considered. The second rockburst event in the area resulted in mining activities being temporarily halted in the Mist orebody. A GRB was convened to consider how best to extract the diminishing pillar and manage the seismic hazard. The review focused on the extraction sequence in the diminishing pillar and the Mist orebody and ground support design, including design methodologies, requirements and the input parameters.

The GRB recommended the diminishing pillar extraction sequence should be changed from the planned quad lift stope to a single lift stoping sequence in order to re-establish the en echelon stoping fronts. The GRB also made recommendations on ground support upgrades but were unable to provide definitive guidelines on ground support design methodologies for dynamic loading conditions. They advised that empirical design chart could be developed in time and that consideration should also be given to inputs used on neighbouring mines when applying the Canadian Rockburst Support Handbook (Kaiser et al. 1996) method.

The recommendations from the GRB have been implemented successfully with the first single lift stope in the diminishing pillar being extracted without any geotechnical issues. A conservative design approach to ground support systems in dynamic conditions was adopted based on the Kaiser et al. (1996) design methodology. The majority of the ground support upgrade has been completed beyond the GRB recommendations.

\section{Acknowledgement}

The authors would like to thank the management of Evolution's Frog's Leg underground mine for permission to publish and present the paper. The paper was also contributed to by Andrew Howie, Daryl Slade and Tim Brickell from the Frog's Leg technical services department. The authors would also like to express their appreciation to the Geotechnical Review Board team that included Chris Langille, Peter Mikula, and Mike Sandy.

\section{References}

Brady, BHG \& Brown, ET 2004, Rock Mechanics for Underground Mining, Kluwer Academic Publishers, London.

Dunn, M 2016, Geotechnical Review Board Summary and Implementation Progress, internal Evolution Mining report, Evolution Mining, Perth.

Human, L 2016a, Dynamic ground support design variation FoS calculations-Stage 2, internal Evolution Mining report, Mungari Operation, Kalgoorlie.

Human, L 2016b, Preliminary numerical modelling results - Mist diminishing pillar, internal Evolution Mining report, Mungari Operation, Kalgoorlie.

Institute of Mine Seismology 2015, Intermediate and long term seismic hazard at Frog's Leg Mine, consultancy report prepared for La Mancha Resources Australia, Mungari Operation, Kalgoorlie.

Institute of Mine Seismology 2016, Development of ground motion prediction equation for Frog's Leg Mine, consultancy report prepared for Evolution Mining, Mungari Operation, Kalgoorlie.

Kaiser, PK, McCreath, D \& Tannant, D 1996, Canadian Rockburst Support Handbook (CRSH), Geomechanics Research Centre, Laurentian University, Sudbury.

Langille, C 2016, Geotechnical and seismic management review-Frog's Leg Mine, Northwind Enterprises consultancy report prepared for Evolution mining, Mungari Operation, Kalgoorlie, pp. 12.

Map 3D International Ltd 2017, Map3D, version 64, viewed 8 January 2017, http://www.map3d.com 
Mgumbwa, J \& Nester, T 2014, 'Paste improvement at La Mancha's Frog's Leg underground mine', in Y Potvin \& T Grice (eds), Proceedings of the 11th International Symposium on Mining with Backfill, Australian Centre for Geomechanics, Perth, pp. 281-294.

Mikula, P 2012, 'Progress with empirical performance charting for confident selection of ground support in seismic conditions', Transactions of the Institutions of Mining and Metallurgy: Section A, vol. 121, no. 5, pp. 192-203.

Mikula, P 2016, Frog's Leg Seismic ground supports review, Mikula Geotechnics consultancy report prepared for Evolution Mining, Mungari Operation, Kalgoorlie.

Simser, BP 2007, 'Strategic and tactical approaches for mining at depth at Xstrata's Craig Mine', in Y Potvin, J Hadjigeorgiou \& TR Stacey (eds), Challenges in Deep and High Stress Mining, Australian Centre for Geomechanics, Perth, pp. 435-443.

Turner, M \& Beck, D 2007, 'Monitoring the onset of seismicity', in Y Potvin, J Hadjigeorgiou \& TR Stacey (eds), Challenges in Deep and High Stress Mining, Australian Centre for Geomechanics, Perth, pp. 181-188.

Villaescusa, E 2014, Geotechnical Design for Sublevel Open Stoping, Taylor and Francis, London.

Villaescusa, E \& Machuca, L 2011, Stress Measurements From Oriental Core Using the WASM AE Acoustic Emission Method, Frog's Leg Mine, consultancy report prepared for La Mancha Resources Australia by Western Australia School of Mines, Curtin University, Kalgoorlie.

Villaescusa, E, Seto, M \& Baird, G 2002, 'Stress measurements from oriented core', International Journal of Rock Mechanics and Mining Sciences, vol. 39, pp. 603-615. 